Case Report

\title{
Clival Ectopic Pituitary Adenoma Mimicking a Chordoma: Case Report and Review of the Literature
}

\author{
Constantine L. Karras, ${ }^{1}$ Isaac Josh Abecassis, ${ }^{2}$ Zachary A. Abecassis, ${ }^{3}$ Joseph G. Adel, ${ }^{3,4}$ \\ Esther N. Bit-Ivan, ${ }^{5}$ Rakesh K. Chandra, ${ }^{6}$ and Bernard R. Bendok ${ }^{3,4}$ \\ ${ }^{1}$ The Ohio State University College of Medicine, Columbus, OH 43212, USA \\ ${ }^{2}$ Department of Neurological Surgery, University of Washington, Seattle, WA 98122, USA \\ ${ }^{3}$ Feinberg School of Medicine, Northwestern University, Chicago, IL 60611, USA \\ ${ }^{4}$ Department of Neurological Surgery, Northwestern University, Chicago, IL, USA \\ ${ }^{5}$ Department of Pathology, Feinberg School of Medicine, Northwestern University, Chicago, IL 60611, USA \\ ${ }^{6}$ Department of Otolaryngology, Feinberg School of Medicine, Northwestern University, Chicago, IL 60611, USA
}

Correspondence should be addressed to Isaac Josh Abecassis; abecassi@uw.edu

Received 3 November 2015; Accepted 14 December 2015

Academic Editor: Mehmet Turgut

Copyright (C) 2016 Constantine L. Karras et al. This is an open access article distributed under the Creative Commons Attribution License, which permits unrestricted use, distribution, and reproduction in any medium, provided the original work is properly cited.

Background. Purely ectopic pituitary adenomas are exceedingly rare. Here we report on a patient that presented with an incidental clival mass thought to be a chordoma. Endonasal resection, tumor pathology, and endocrinology workup revealed a prolactinoma. Case Presentation. A 41-year-old male presented with an incidental clival lesion presumed to be a chordoma. On MRI it involved the entire clivus, extended laterally to the petroclival junction, and invaded the cavernous sinuses bilaterally, encasing both internal carotid arteries, without direct extension into the sella. Intraoperatively, it was clear that the tumor originated from the clivus and that the sellar dura was completely intact. Frozen-section pathology was consistent with a pituitary adenoma. Immunostaining was positive for synaptophysin and prolactin with a low Ki-67 index, suggestive of a prolactinoma. Additional immunohistochemical stains seen in chordomas (EMA, S100, and Brachyury) and other metastatic tumors were negative. A postoperative endocrine workup revealed an elevated serum prolactin of $881.3 \mathrm{ng} / \mathrm{mL}$ (normal <20). Conclusions. In conclusion, it is crucial to maintain an extensive differential diagnosis when evaluating a patient with a clival lesion. Ectopic clival pituitary adenomas, although rare, may warrant an endocrinological workup preoperatively as the majority may respond to medical treatment.

\section{Introduction}

Pituitary adenomas are the most common cause of a sellar or parasellar mass, comprising about 10 to 15 percent of all intracranial tumors $[1,2]$. It is well documented that pituitary adenomas have the capacity to invade adjacent and nearby structures, most commonly the sphenoid sinus [3]. Less commonly, pituitary adenomas may also involve the cavernous sinus, suprasellar region, nasopharynx, and rarely the clivus [4]. Purely ectopic pituitary adenomas are extremely unusual and must be confirmed via imaging and intraoperative visualization to be completely separate from an intact pituitary gland and the sella turcica. Here we report on a patient that presented with an incidental clival mass thought to be a chordoma. Endonasal resection, pathology of the tumor, and endocrinology workup revealed a purely ectopic prolactin-secreting pituitary adenoma.

\section{Case Report}

Our patient was a 41-year-old right-handed male who presented with an incidental clival lesion, originally presumed to be a chordoma. Subjectively, the patient reported no neurological complaints. The patient's medical history was significant only for chronic neck and lower back pain and there were no noteworthy findings on physical examination, 


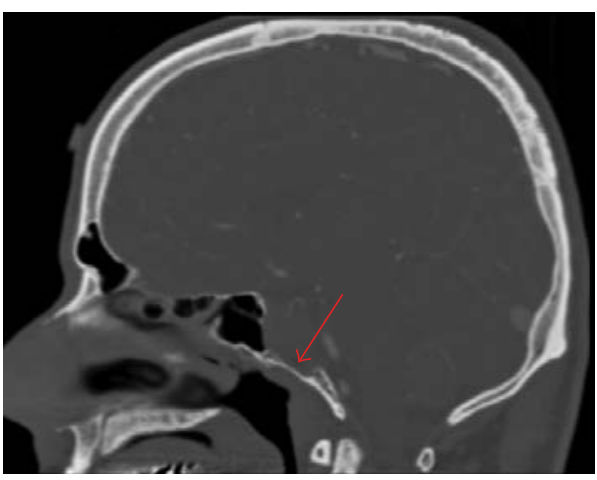

(a)

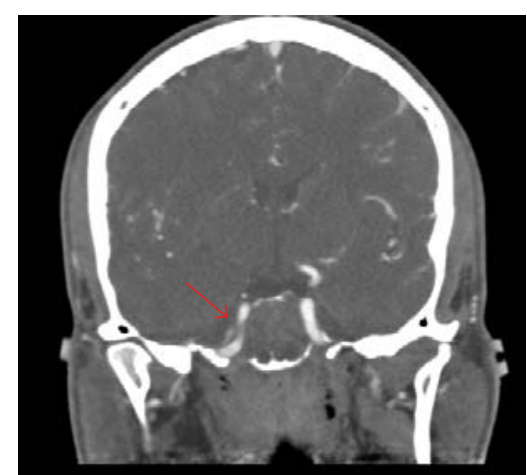

(b)

FIGURE 1: Preoperative computed tomography angiogram (CTA) scan, sagittal bone window (a) and coronal vascular window (b) sections, showing poorly vascularized clival mass that erodes the clivus (a) and encases the right internal carotid artery (b).

which included a thorough neurological exam. His complete blood count, chemistry panel, and metabolic panel were all normal.

Repeat magnetic resonance imaging (MRI) revealed an enhancing lesion measuring $1.7 \times 2.6 \times 3.2 \mathrm{~cm}$ that involved the entire clivus, extended laterally to the petroclival junction, and invaded the cavernous sinuses bilaterally with further encasement of the internal carotid arteries (ICAs) bilaterally, without direct extension into the sella (Figures 1(a)1(b) and 2(a)-2(c)). This lesion was stable in comparison to outside hospital images. The case was discussed at an interdisciplinary brain tumor meeting and, ultimately, the patient was advised to undergo surgical resection via an endoscopic endonasal approach. Intraoperatively, it was very clear that the tumor originated from the clivus and that the sellar dura was completely intact. The frozen-section pathology surprisingly was consistent with a pituitary adenoma. Accordingly, a decision was made perioperatively to proceed with only partial resection due to the potential for medical management of most functional adenomas postoperatively and the risks associated with complete resection given the complex distribution of the lesion. The patient had no complications and was discharged home on postoperative day 2.

Postoperative imaging revealed expected residual enhancing lesions along the petroclival junctions bilaterally and on the right cavernous sinus near the right ICA (Figures 3(a) and 3(b)). Immunostaining of the tumor tissue demonstrated an epithelial neoplasm that stained positive for synaptophysin and prolactin with a low Ki-67 index (Figures 4(a) $-4(\mathrm{~d})$ ), suggestive of a prolactin-secreting pituitary adenoma. Additional immunohistochemical stains seen in chordomas (EMA, S100, and Brachyury) and other metastatic tumors were negative. A postoperative endocrine workup (Table 1) revealed an elevated serum prolactin of $881.3 \mathrm{ng} / \mathrm{mL}$ (normal male $<20 \mathrm{ng} / \mathrm{mL}$ ). The patient was referred to an endocrinologist and began dopamine agonist (cabergoline) therapy given his prolactin level and residual tumor. He has since been followed up for over 1 year with monthly visits. His most recent prolactin level (11 months postoperatively)
TABle 1: Patient's endocrinological lab values.

\begin{tabular}{lcc}
\hline & Patient & Reference range \\
\hline Free T4 $(\mathrm{ng} / \mathrm{dL})$ & 0.7 & $0.7-1.5$ \\
TSH $(\mu \mathrm{IU} / \mathrm{mL})$ & 2.58 & $0.4-4.0$ \\
Prolactin $(\mathrm{ng} / \mathrm{mL})$ & 881.3 & $2.6-13.1$ \\
FSH $(\mathrm{mlU} / \mathrm{mL})$ & 3 & $1.0-8.0(\mathrm{Men})$ \\
$\mathrm{LH}(\mathrm{mlU} / \mathrm{mL})$ & 3.1 & $2.0-12.0(\mathrm{Men})$ \\
Cortisol, $2 \mathrm{PM}(\mu \mathrm{g} / \mathrm{dL})$ & 6.8 & $0-25$ \\
Total testosterone $(\mathrm{ng} / \mathrm{dL})$ & 290 & $250-1100$ \\
Free testosterone $(\mathrm{pg} / \mathrm{mL})$ & 58.4 & $35-155$ \\
\hline
\end{tabular}

$\mathrm{T} 4$ = thyroxine hormone.

TSH $=$ thyroid stimulating hormone

$\mathrm{FSH}=$ follicle stimulating hormone.

$\mathrm{LH}=$ luteinizing hormone.

was $20.6 \mathrm{ng} / \mathrm{mL}$; his lowest level was $15.2 \mathrm{ng} / \mathrm{mL}$, collected 6 months postoperatively. He remains neurologically intact.

\section{Discussion}

Clival tumors are generally rare, comprising $1 \%$ of all intracranial neoplasms. The differential diagnosis for a clival lesion is vast, including chordoma most commonly (40\%), meningioma, chondrosarcoma, astrocytoma, craniopharyngioma, germ cell tumor, non-Hodgkin's lymphoma, melanoma, metastatic carcinoma, and rarely pituitary adenoma [4]. Our patient was presumed to have a chordoma based on the radiographic characteristics and the tumor location. Clival chordomas are typically managed with gross total resection with proton beam therapy. There has been one previous report of an ectopic pituitary adenoma thought to be a chordoma [12] and vice versa [4].

Ectopic pituitary adenomas are thought to arise from residual cells along the migration tract of the pharyngeal pituitary as it travels from Rathke's pouch to the sella turcica. The anterior portion of the pituitary initially develops as a pharyngeal outpouching of epithelial ectoderm, known as Rathke's pouch. Around week 8 of gestation, a portion 


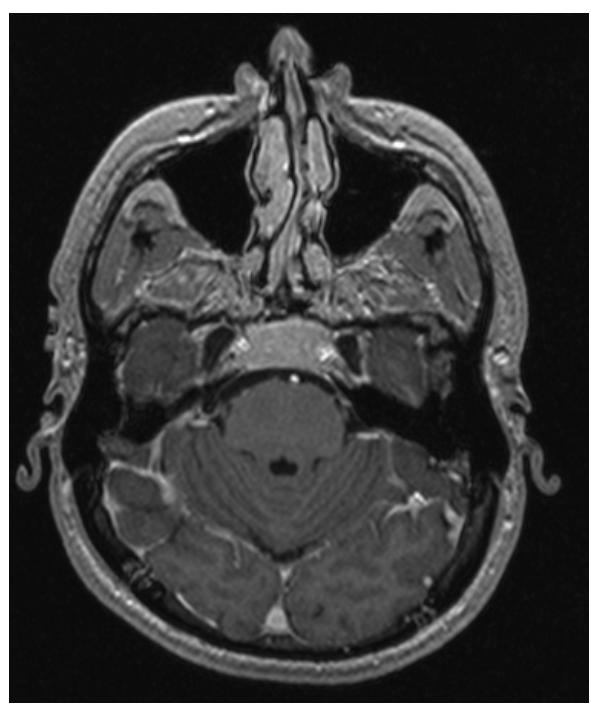

(a)

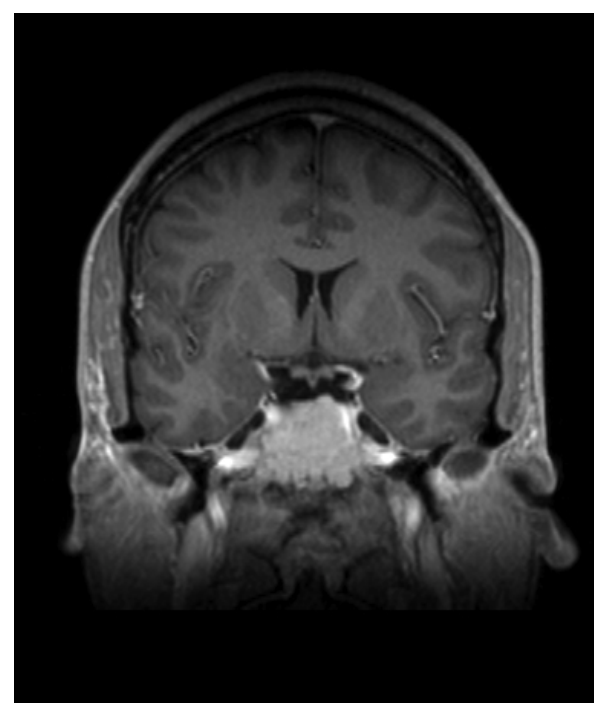

(b)

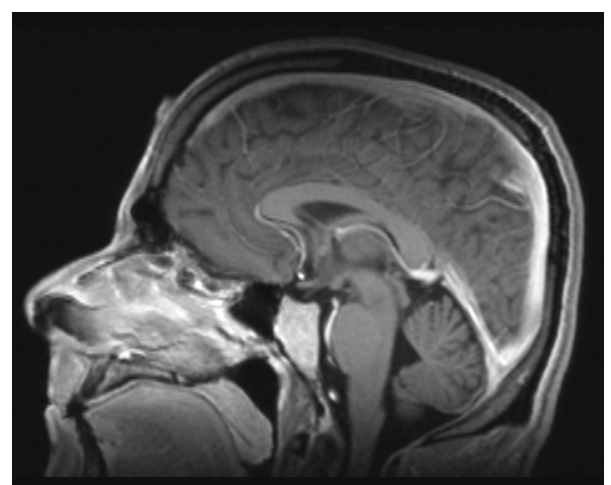

(c)

FIGURE 2: Preoperative magnetic resonance imaging, with contrast, axial (a), coronal (b), and sagittal (c) sections, demonstrating contrast enhancing, clival tumor.

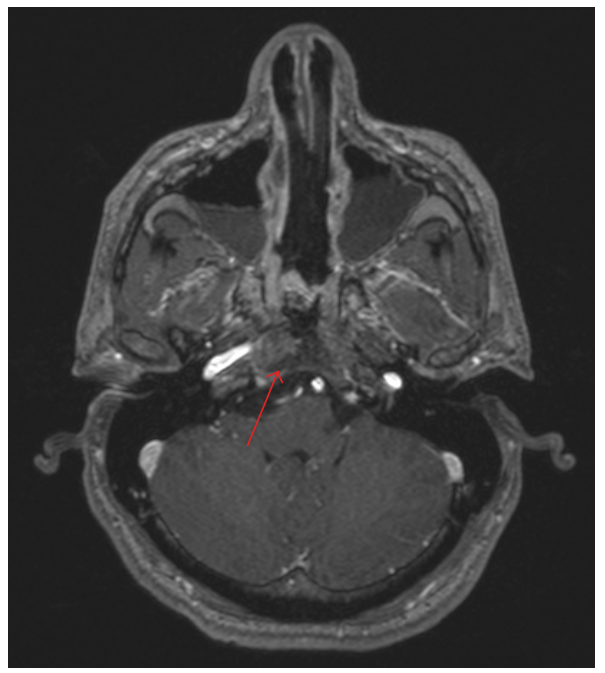

(a)

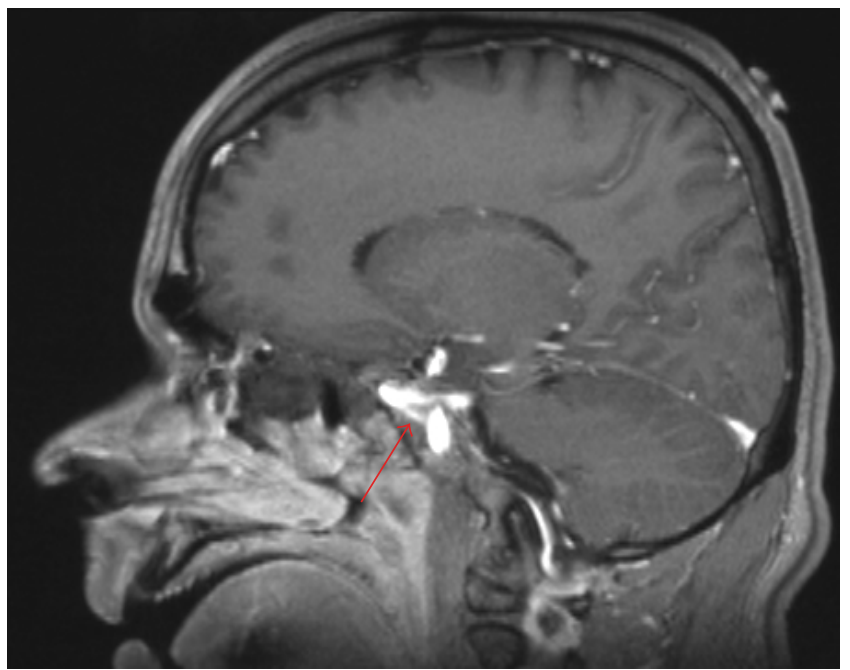

(b)

FIGURE 3: Postoperative magnetic resonance imaging, with contrast, axial (a) and sagittal (b) sections, demonstrating a small amount of residual tumor. 


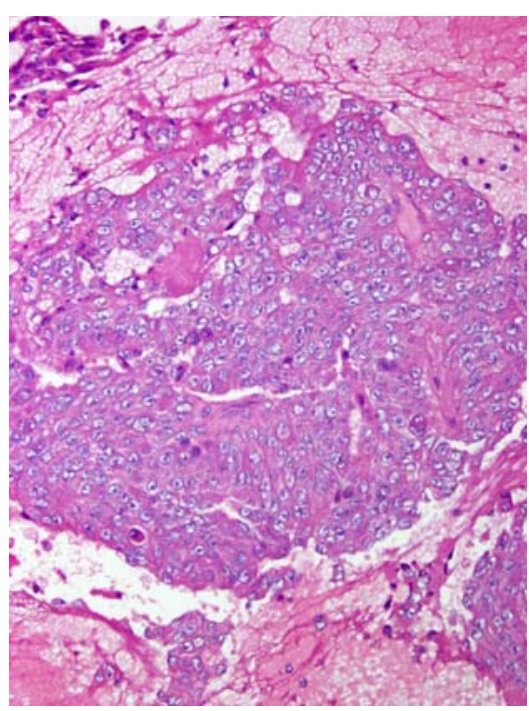

(a)

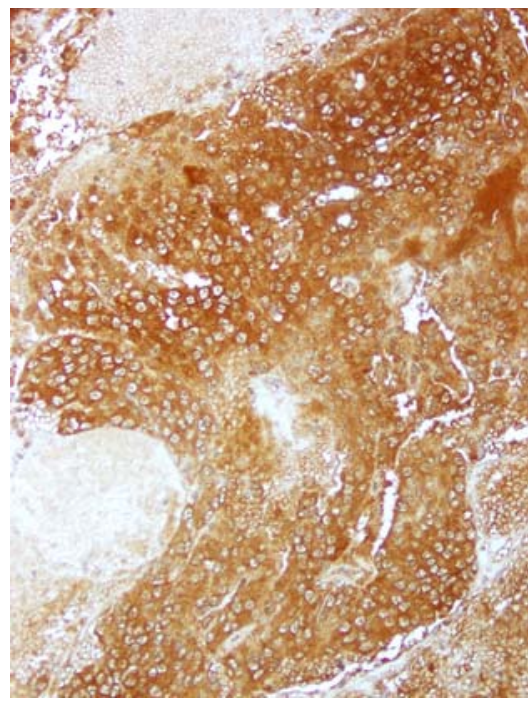

(c)

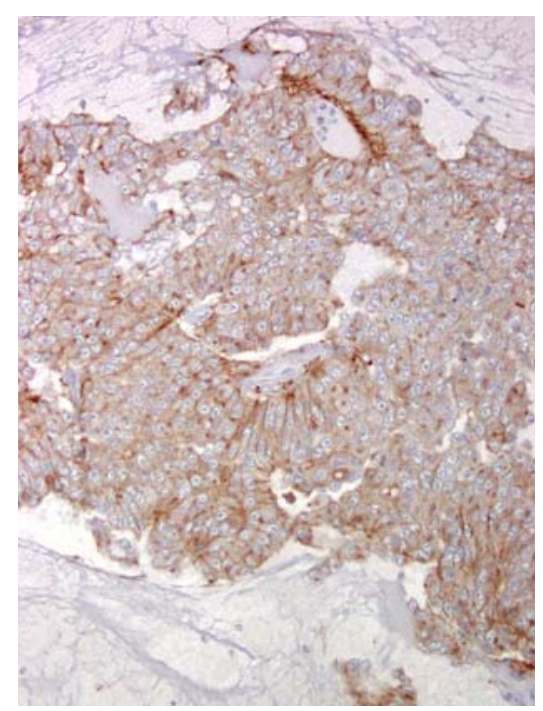

(b)

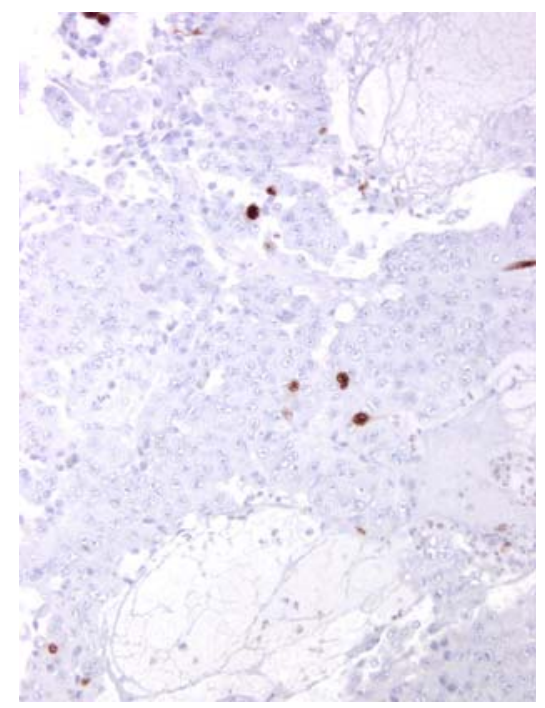

(d)

FIGURE 4: Pathologic evaluation, all at 20x magnification. (a) Histologic sections demonstrate an epithelial neoplasm composed of monomorphic cells with increased nuclear to cytoplasmic ratios and prominent nucleoli. (b) Immunohistochemical staining positive for synaptophysin. (c) Prolactin diffusely and strongly labels the neoplastic cells. (d) The proliferation index is approximately $2 \%$ on Ki-67 staining.

separates and migrates through the craniopharyngeal canal into the sella, forming the anterior portion of the pituitary, from which most pituitary adenomas arise $[9,16]$. Ectopically deposited cells can rarely develop into adenomas anywhere along this tract, though. There have been over 100 descriptions of ectopic pituitary adenomas in the literature, most originating in the sphenoid sinus [17]. The first reported, in 1901, was an ectopic pituitary adenoma [10] located in the sphenoid sinus that presented with acromegaly. However, purely ectopic clival pituitary adenomas-that is, tumors that originate in the clivus with no involvement of the pituitary gland-are exceedingly rare.

We encountered 16 prior reported cases of clival ectopic pituitary adenomas (Table 2) [4-9, 11-14, 17-21]. They seem to be fairly equally distributed between genders ( 9 males, 8 females) and the median age at presentation was 50 years old.

Like pituitary adenomas, ectopic tissue can be categorized by size as either a macroadenoma $(>1 \mathrm{~cm})$ or microadenoma $(<1 \mathrm{~cm})$. The tumor can be further classified as functional (65\% of nonectopic adenomas) or nonfunctional based on whether or not the cell type is hormone-secreting. Prolactinsecreting pituitary adenomas (nonectopic) are the most common and comprise $48 \%$ of all functional adenomas [22]. Occasionally, pituitary adenomas can lack the cardinal features found on light microscopy and immunohistochemical staining that were present in our case. Electron microscopy of these tumors may aid in further classification of the cell type based on appearance of the nucleus, cytoplasm, organelles 


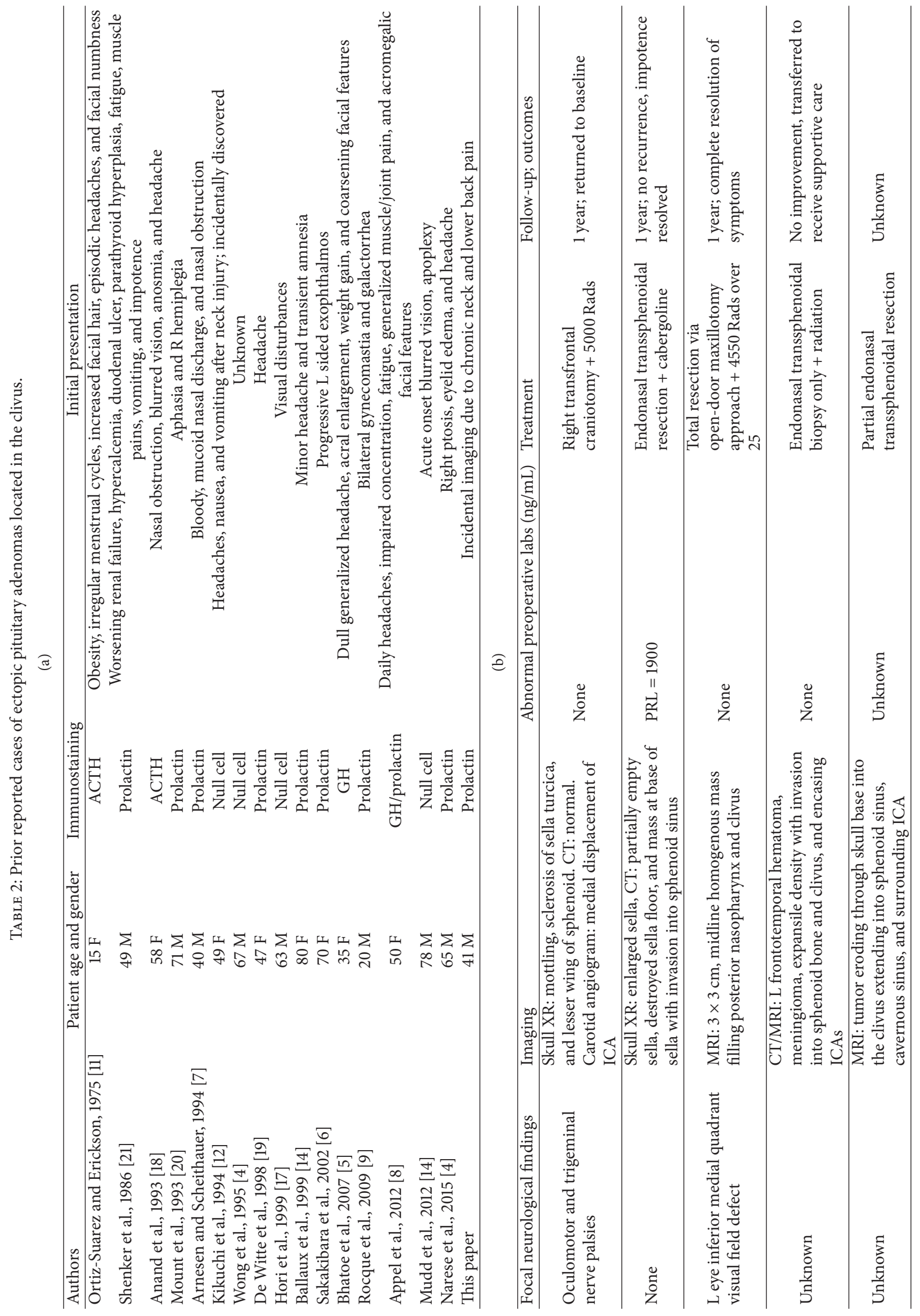




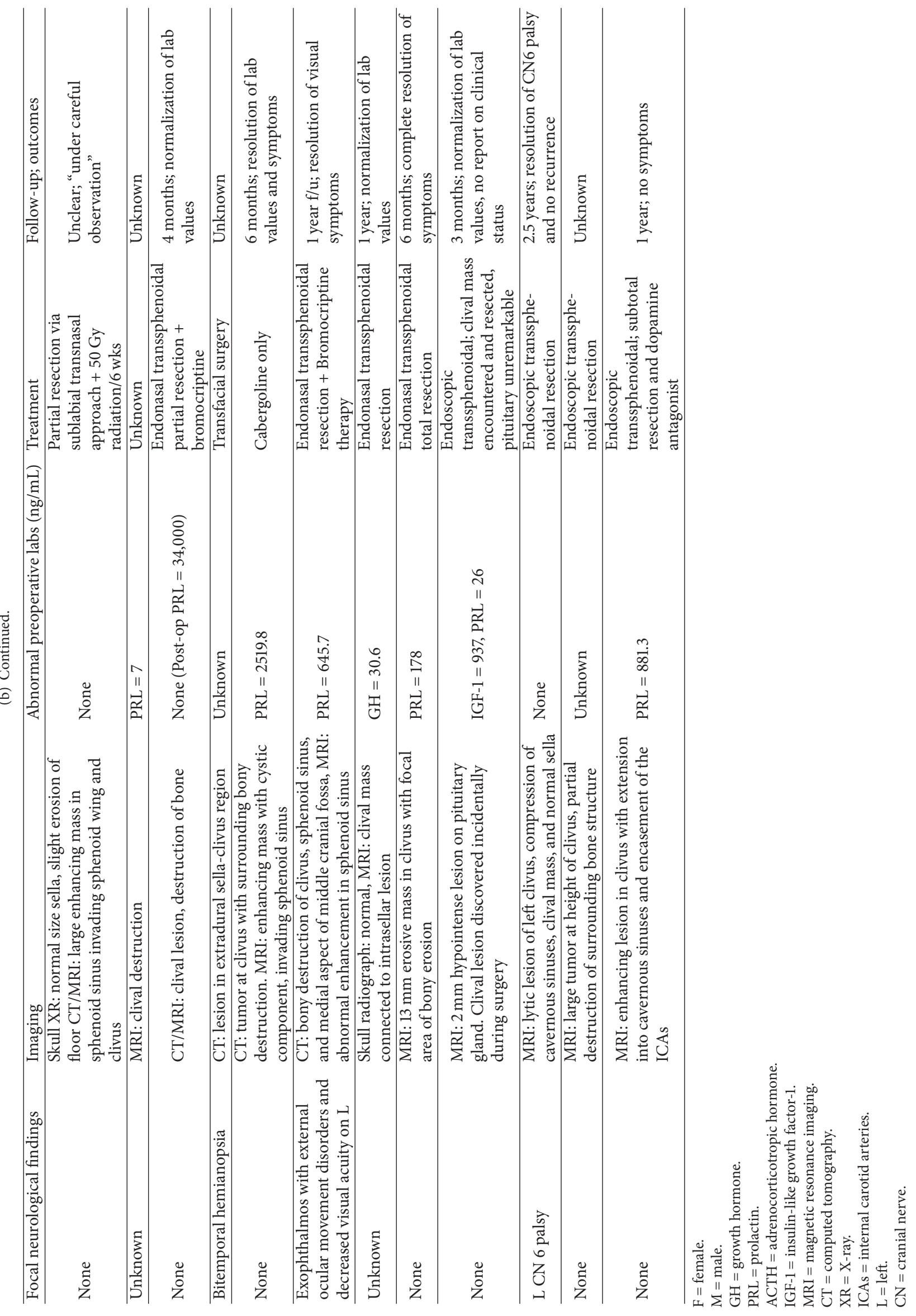


(including rough endoplasmic reticulum and Golgi apparatus), and granule morphology [7].

Analysis of Table 2 reveals that 10/17 clival ectopic pituitary tumors described were prolactinomas, 2/17 secreted ACTH, 2/17 secreted GH, and only 4/17 were nonfunctional-one tumor secreted both prolactin and $\mathrm{GH}$ [8]. Some (especially nonfunctional tumors) presented asymptomatically or with focal neurological deficits (5/17 cases) due to compression of nearby structures. The most common theme among patient presentations in the literature review was "frequent headache" in the period leading up to diagnosis. Pituitary adenomas often classically present with bitemporal hemianopsia, but ectopic adenomas typically do not unless they happen to involve the optic chiasm. One case presented as pituitary apoplexy-tumor infarction or hemorrhage resulting in a constellation of symptoms that may include headache, visual deficits, ophthalmoplegia, or altered mental status [13]. Most of these findings are nonspecific, however, and cannot distinguish a pituitary adenoma from other lesions such as a chordoma.

Fortunately, a surprising 76\% (13/17) of reported cases were functional adenomas, permitting a possible preoperative diagnosis based on history, physical exam, and basic labs alone. ACTH-secreting adenomas may present with Cushing's syndrome (moon facies, truncal obesity, abdominal striae, hirsutism, etc.), characterized by hypercortisolism and an abnormal dexamethasone suppression test. GH-secreting adenomas may manifest as acromegaly in adults, which presents with enlargement of the extremities, coarse facies (frontal bossing, prognathism), carpal tunnel syndrome, diabetes, or cardiomyopathy-labs would reveal elevated IGF-1 (insulin-like growth factor) and a failed oral glucose tolerance test. Prolactinomas, which comprised the majority of cases (10/17), may present with gynecomastia, erectile dysfunction, decreased libido, galactorrhea, amenorrhea (in females), and an elevated prolactin level. Of note, after a more focused history following our postoperative diagnosis of prolactinoma, it was discovered retrospectively that our patient had actually had a significant drop in libido throughout the previous 7-8 years.

Our case was unique in that it was the first reported clival ectopic pituitary adenoma that invaded both cavernous sinuses and the internal carotid arteries, making it the most aggressive tumor of all reported cases-this is unusual for adenomas, as they typically are quite less infiltrative. This is why it was originally confused for a chordoma, but it is particularly important to maintain pituitary adenomas on the differential for sphenoidal or clival lesions because the diagnosis can have significant implications on the management of the tumor. For example, dopamine agonists (cabergoline, bromocriptine) and somatostatin analogs (octreotide, lanreotide) or GH antagonists (pegvisomant) are first-line therapy for prolactinomas and $\mathrm{GH}$-secreting adenomas, respectively, depending on the clinical symptoms and anatomical distribution of the tumor. They may be used as monotherapy or as adjunctive treatment for tumor shrinkage. With 76\% (13/17) of reported clival ectopic adenomas being hormone-secreting and $85 \%(11 / 13)$ of these being susceptible to medical management ( $\mathrm{GH}$ - or prolactin-secreting), a significant opportunity exists for more conservative management if the diagnosis can be made preoperatively rather than retrospectively based on histology. This is especially useful for more aggressive tumors (such as our patient's, which invaded the cavernous sinus), where a complete resection may carry significant risk of bleeding and morbidity. Adjunctive pharmacotherapy can also potentially delay or even eliminate the need for surgery, especially in elderly individuals or in those with significant medical comorbidities and relative contraindications to surgery.

A common theme among reported cases, including ours, was that the correct diagnosis was made histologically rather than preoperatively. Management could have been drastically altered in most of these cases had a more focused, thorough history and physical exam alone occurred.

\section{Conclusions}

In conclusion, it is important to maintain an extensive differential diagnosis when evaluating a patient with a clival lesion. Ectopic clival pituitary adenomas, although rare, warrant consideration as the majority respond to pharmacotherapy [14] and thus are managed much differently than lesions such as chordomas. The diagnosis can easily be screened for with a focused history and physical exam directed toward symptoms of the most common types (prolactin-, GH-, and ACTHsecreting adenomas), which make up the majority (76\%) of reported clival ectopic adenomas. If the history and physical exam yield a positive screen, a preoperative endocrinological workup is necessary to confirm the diagnosis.

\section{Conflict of Interests}

The authors declare that they have no conflict of interests.

\section{References}

[1] P. J. Pernicone and B. W. Scheithauer, "Invasive pituitary adenomas and pituitary carcinomas," in Surgical Pathology of the Pituitary Gland, R. V. Lloyd, Ed., pp. 121-136, WB Saunders, Philadelphia, Pa, USA, 1993.

[2] T. Terada, K. Kovacs, L. Stefaneanu, and E. Horvath, "Incidence, pathology, and recurrence of pituitary adenomas: study of 647 unselected surgical cases," Endocrine Pathology, vol. 6, no. 4, pp. 301-310, 1995.

[3] F. Tovi, M. Hirsch, M. Sacks, and A. Leiberman, "Ectopic pituitary adenoma of the sphenoid sinus: report of a case and review of the literature," Head and Neck, vol. 12, no. 3, pp. 264$268,1990$.

[4] K. Wong, J. Raisanen, S. L. Taylor, M. W. McDermott, C. B. Wilson, and P. H. Gutin, "Pituitary adenoma as an unsuspected clival tumor," The American Journal of Surgical Pathology, vol. 19, no. 8, pp. 900-903, 1995.

[5] H. S. Bhatoe, N. Kotwal, and S. Badwal, "Clival pituitary adenoma with acromegaly: case report and review of literature," Skull Base, vol. 17, no. 4, pp. 265-268, 2007.

[6] Y. Sakakibara, H. Sekino, Y. Taguchi, and M. Tadokoro, "Unilateral exophthalmos caused by a prolactin producing ectopic pituitary adenoma: case report," Neurological Surgery, vol. 30, no. 6, pp. 623-628, 2002. 
[7] M. Arnesen and B. W. Scheithauer, "Aggressive small cell tumor of the skull base," Ultrastructural Pathology, vol. 18, no. 1-2, pp. 191-197, 1994.

[8] J. G. Appel, M. Bergsneider, H. Vinters, N. Salamon, M. B. Wang, and A. P. Heaney, "Acromegaly due to an ectopic pituitary adenoma in the clivus: case report and review of literature," Pituitary, vol. 15, supplement 1, pp. S53-S56, 2012.

[9] B. G. Rocque, K. A. G. Herold, M. S. Salamat, Y. Shenker, and J. S. Kuo, "Symptomatic hyperprolactinemia from an ectopic pituitary adenoma located in the clivus," Endocrine Practice, vol. 15, no. 2, pp. 143-148, 2009.

[10] J. Erdheim, "Über einen hypophysentumor von ungewöhnlichem," Beiträge zur Pathologischen Anatomie und zur Allgemeinen Pathologie, vol. 46, pp. 233-240, 1909.

[11] H. Ortiz-Suarez and D. L. Erickson, "Pituitary adenomas of adolescents," Journal of Neurosurgery, vol. 43, no. 4, pp. 437-439, 1975.

[12] K. Kikuchi, M. Kowada, J. Sasaki, and M. Sageshima, "Large pituitary adenoma of the sphenoid sinus and the nasopharynx: report of a case with ultrastructural evaluations," Surgical Neurology, vol. 42, no. 4, pp. 330-334, 1994.

[13] P. A. Mudd, S. Hohensee, K. O. Lillehei, T. T. Kingdom, and B. K. Kleinschmidt-DeMasters, "Ectopic pituitary adenoma of the clivus presenting with apoplexy: case report and review of the literature," Clinical Neuropathology, vol. 31, no. 1, pp. 24-30, 2012.

[14] D. Ballaux, J. Verhelst, B. Pickut, P. P. De Deyn, and C. Mahler, "Ectopic macroprolactinoma mimicking a chordoma: a case report," Endocrine-Related Cancer, vol. 6, no. 1, pp. 117-122, 1999.

[15] D. Narese, V. Virzì, G. Virzì et al., "Ectopic prolactinoma in the clivus: a case report," La Clinica Terapeutica, vol. 166, no. 4, pp. 176-178, 2015.

[16] W. J. Hamilton, J. D. Boyd, and H. W. Mossman, "Prenatal development of form and function," in Human Embryology, Heffer and Sons Ltd, pp. 345-346, Cambridge, UK, 1945.

[17] A. Hori, D. Schmidt, and E. Rickels, "Pharyngeal pituitary: development, malformation, and tumorigenesis," Acta Neuropathologica, vol. 98, no. 3, pp. 262-272, 1999.

[18] V. K. Anand, C. M. Osborne, and H. L. Harkey III, "Infiltrative clival pituitary adenoma of ectopic origin," OtolaryngologyHead and Neck Surgery, vol. 108, no. 2, pp. 178-183, 1993.

[19] O. De Witte, N. Massager, I. Salmon, S. Meyer, G. Dooms, and J. Brotchi, "Ectopic prolactinoma in the clivus," Acta Chirurgica Belgica, vol. 98, no. 1, pp. 10-13, 1998.

[20] S. L. Mount, D. J. Taatjes, and T. D. Trainer, "Ultrastructural study of a pituitary adenoma (prolactinoma) within the clivus bone using immunoelectron microscopy," Ultrastructural Pathology, vol. 17, no. 6, pp. 637-642, 1993.

[21] Y. Shenker, R. V. Lloyd, L. Weatherbee, F. K. Port, R. J. Grekin, and A. L. Barkan, "Ectopic prolactinoma in a patient with hyperparathyroidism and abnormal sellar radiography," Journal of Clinical Endocrinology and Metabolism, vol. 62, no. 5, pp. 1065-1069, 1986.

[22] B. M. Biller, B. Swearingen, N. T. Zervas, and A. Klibanski, "A decade of the massachusetts general hospital neuroendocrine clinical center," The Journal of Clinical Endocrinology \& Metabolism, vol. 82, no. 6, pp. 1668-1674, 1997. 


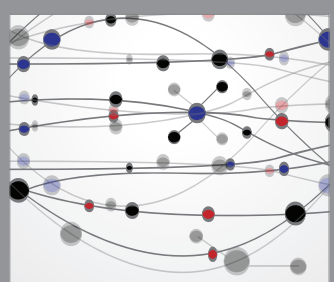

The Scientific World Journal
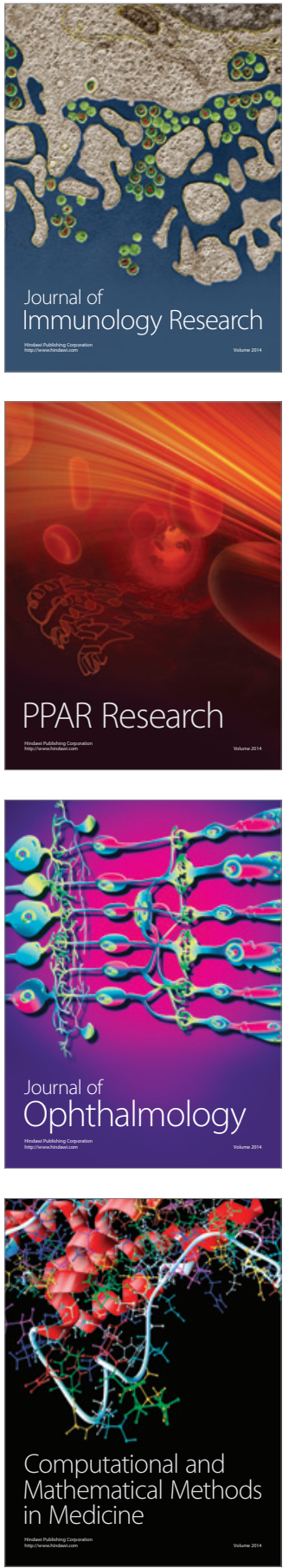

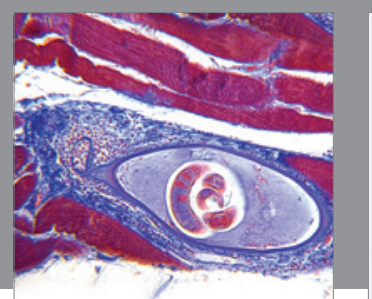

Gastroenterology Research and Practice

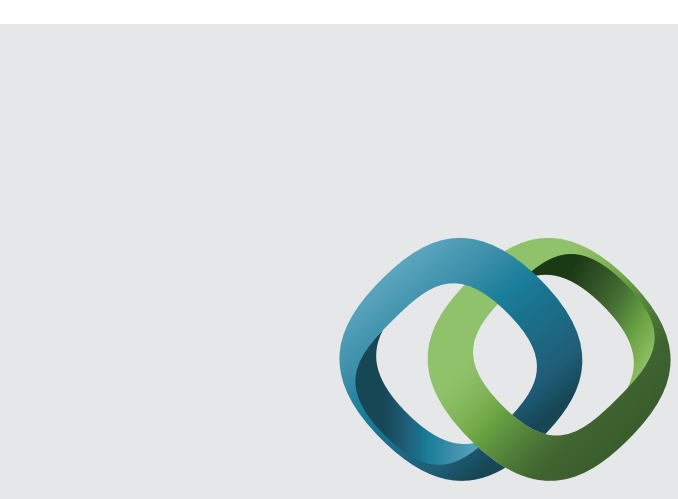

\section{Hindawi}

Submit your manuscripts at

http://www.hindawi.com
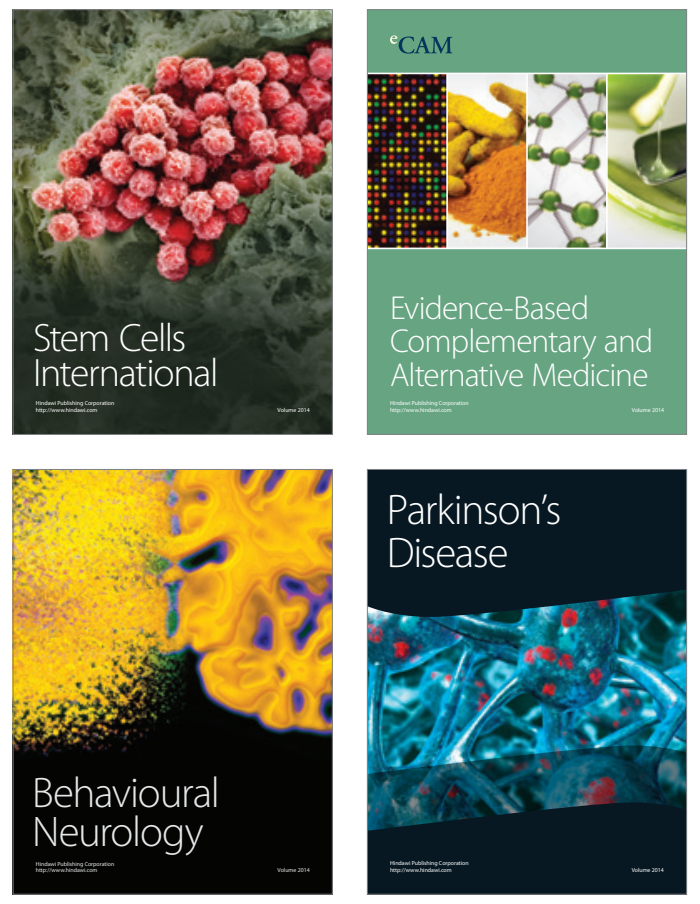
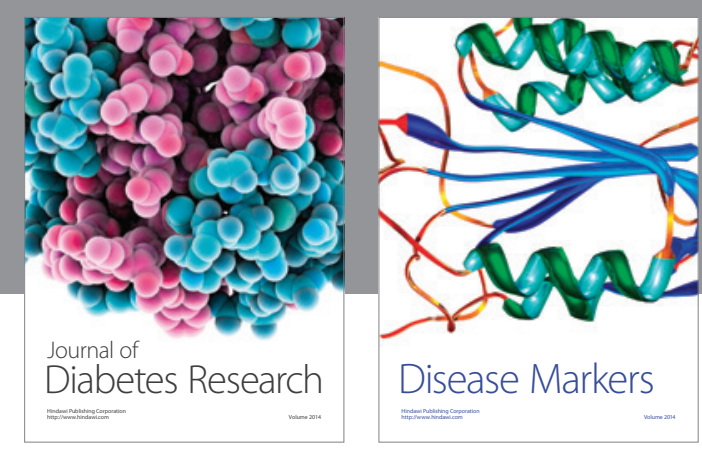

Disease Markers
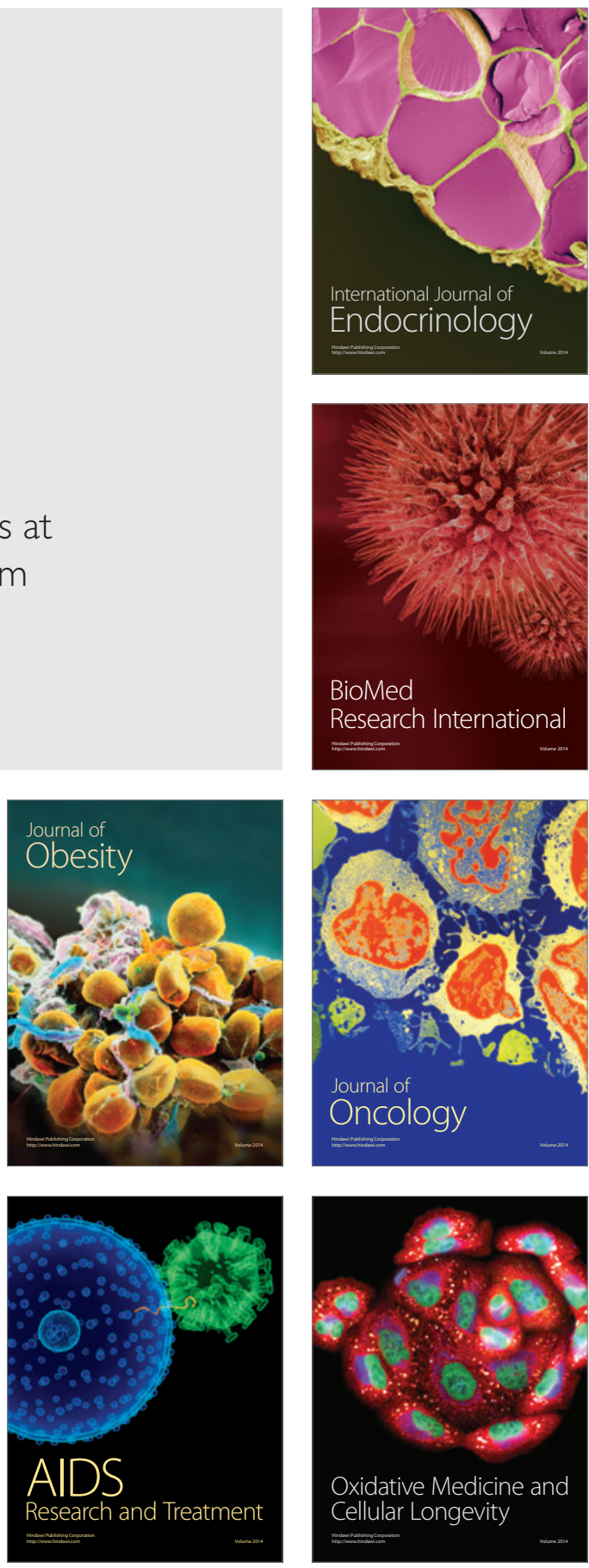